\title{
Head and neck cancer and occupational exposure to leather dust: results from the ICARE study, a French case-control study
}

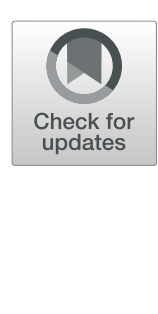

Loredana Radoï ${ }^{1,2^{*}}$ (D), Fatoumata Sylla ${ }^{1,3}$, Mireille Matrat ${ }^{1,4,5}$, Christine Barul ${ }^{6}$, Gwenn Menvielle ${ }^{7}$, Patricia Delafosse ${ }^{8}$, Isabelle Stücker ${ }^{1}$, Danièle Luce $^{6}$ and ICARE study group

\begin{abstract}
Background: Leather dust is an established carcinogen of the sinonasal cavities; however, evidence is lacking regarding its association with other head and neck cancers (HNC). To date, few studies have been conducted on the association between occupational leather dust exposure and the risk of oral, pharyngeal, and laryngeal cancers. The objective of this study was to investigate the association between the risk of HNC and occupational exposure to leather dust.
\end{abstract}

Methods: Lifestyle habits and occupational history were collected for 2161 patients with squamous cell carcinoma of oral cavity, pharynx, and larynx, and 3555 controls, using a standardized questionnaire. Occupational exposure to leather dust was assessed using a job-exposure matrix. Odds ratios (OR) and 95\% confidence intervals (Cl) for HNC globally and by subsite were estimated using multivariate unconditional, and polytomous logistic regressions, respectively.

Results: Cumulative lifetime exposure to leather dust $<6 \mathrm{mg} / \mathrm{m}^{3}$-years was associated with an increased risk of laryngeal cancer $(\mathrm{OR}=2.26,95 \% \mathrm{Cl}: 1.07-4.76)$; higher levels were not related to elevated risks of HNC. Some tasks performed and the use of some glues were associated with elevated, although non-significant, risks of HNC. No dose-response relationships were observed.

Conclusion: Our study did not provide enough evidence for an increased risk of HNC related to occupational exposure to leather dust. Further studies are needed to understand the risks of specific tasks in the leather industry.

Keywords: Leather dust, Occupational health, Head and neck cancer, Epidemiology, Case control study

\section{Introduction}

Head and neck cancers (HNC; excluding sinonasal cancers) accounted for an estimated 11,240 new cases of cancer in France in 2012; this is the third-highest incidence rate and the fourth most frequent cancer among men in Europe [1]. Tobacco smoking and alcohol consumption are well-known major risk factors for oral cavity, pharyngeal and laryngeal cancers [2, 3]. There is also evidence that other factors may contribute to these diseases, including oropharyngeal infection with human

\footnotetext{
* Correspondence: Ioredana.radoi@inserm.fr

'Paris Sud, Paris Saclay University, UVSQ, CESP, INSERM U1018, Environmental Epidemiology of Cancer Team, Villejuif, France

${ }^{2}$ Oral medicine and oral surgery department, University Paris Descartes,

Faculty of Dental surgery, Paris, France

Full list of author information is available at the end of the article
}

papillomavirus (HPV) [4, 5], unbalanced diet [6], poor oral health [7], and low socioeconomic position [8-10]. Exposures to asbestos and strong acid mists are known to be occupational risk factors for laryngeal cancer [11, 12]. Furthermore, risk of laryngeal cancer was associated with exposure to polycyclic aromatic hydrocarbons, engine exhaust, textile dust, and working in the rubber industry [13]. Exposures to asbestos and polycyclic aromatic hydrocarbons were found to be related to an increased risk of oral and pharyngeal cancers [14].

The International Agency for Research on Cancer (IARC) classified occupational exposure to leather dust as carcinogenic to humans [15]. Indeed, there is consistent and strong evidence from epidemiological studies that exposure to leather dust causes cancer of the nasal

(c) The Author(s). 2019 Open Access This article is distributed under the terms of the Creative Commons Attribution 4.0 International License (http://creativecommons.org/licenses/by/4.0/), which permits unrestricted use, distribution, and reproduction in any medium, provided you give appropriate credit to the original author(s) and the source, provide a link to the Creative Commons license, and indicate if changes were made. The Creative Commons Public Domain Dedication waiver (http://creativecommons.org/publicdomain/zero/1.0/) applies to the data made available in this article, unless otherwise stated. 
cavity and paranasal sinuses, particularly in workers employed in the boot and shoe industry [15].

However, studies on occupational exposure to leather dust causing other HNC are conflicting. Only two studies reported results for employment in the leather and leather product industries alone: a case control-study observed slightly more cases of cancers of the oral cavity, pharynx and larynx than expected [16]; a cohort study reported no increased risk of laryngeal cancer [17]. Other studies have explored associations between the risk of HNC and exposure to leather dust, or occupations related to leather work; a case-control study observed a significant excess risk of pharyngeal squamous cell carcinoma associated with exposure to leather dust [18]; two case-control studies reported significantly higher risks of laryngeal and hypopharyngeal cancer for shoe finishers, but not for shoe makers or repairers [19], or for leather workers in general [20]. In addition, a cohort study reported a significantly elevated risk of oral and pharyngeal cancers among shoemakers/cobblers, but no association with exposure to leather dust [21]. Conversely, several studies did not find increased risks of HNC associated with exposure to leather dust, or occupations related to the leather work [17, 22-25].

Using the data from the ICARE study (Investigation of occupational and environmental CAuses of REspiratory cancers study), we aimed to: (i) examine the association between the risk of HNC and occupational exposure to leather dust, overall and by subsite; (ii) analyze this association through materials used, tasks performed, and co-exposure to glues.

\section{Methods}

\section{ICARE study population}

The design of the study has already been reported [26]. Briefly, the ICARE study is a multicenter, populationbased case-control study, conducted between 2001 and 2007, comprising cases of HNC $(n=2415)$ and lung cancer $(n=2926)$, and controls $(n=3555)$. Incident cases were identified in collaboration with the French cancer registries in 10 geographical areas. They were all aged 1875 years at diagnosis, with histologically confirmed primary tumors. Controls were selected from the general population of the geographical areas included in the study by list-assisted random digit dialing sampling and an incidence density sampling method. They were frequencymatched to all cases (lung cancer and HNC) by sex and age. Additional stratification was used to achieve a socioeconomic status (SES) distribution among the controls comparable to that of the general population.

\section{Data collection}

Using a standardized questionnaire, subjects were interviewed face-to-face by trained interviewers to collect information on sociodemographic characteristics, anthropometric measurements, personal and familial history of cancer, lifetime tobacco and alcohol consumption, and entire occupational history. An occupational history questionnaire was designed with the collaboration of industrial hygienists. It included general questions on occupational history. For each job held for at least 1 month, the subject was asked for the job title, duration of employment, activity sector, main and subsidiary tasks, and the description of the work environment. Specific questionnaires (covering 20 job titles, including work in the leather industry) were also designed with more technical questioning.

A shorter version of the general questionnaire was used for subjects who were too sick to answer the complete questionnaire $(10.8 \%$ of cases, and $2.1 \%$ of controls). This shorter questionnaire (answered by the subjects themselves or by their next-of-kin) included mainly information on tobacco and alcohol consumption, and occupational history, without detailed questions on each job held or tasks performed. Therefore, for these subjects, occupations and industries were recovered from the analyses of the general questionnaire. However, they were excluded from the analysis of the leather work questionnaire due to a lack of response to this questionnaire.

Participation rates were $80.6 \%$ among controls, and $82.5 \%$ among cases. Each subject gave written informed consent. The study was approved by the Institutional Review Board of the French National Institute of Health and Medical Research (IRB-Inserm, no. 01-036), and by the French Data Protection Authority (CNIL no. 90120).

\section{Study sample}

The present analysis was restricted to the following $\mathrm{HNC}$ sites as coded by the International Classification of Diseases for Oncology (ICD-O-3) [27]: oral cavity (C00.3-C00.9, C02.0-C02.3, C03.0, C03.1, C03.9, C04.1, C04.8, C04.9, C05.0, C06.0-C06.2, C06.8 and C06.9); oropharynx (C01.9, C02.4, C05.1, C05.2, C09.0, C09.1, C09.8, C09.9, C10.0-C10.4, C10.8, C10.9); hypopharynx (C12.9, C13.0-C13.2, C13.8, C13.9); oral cavity/pharynx unspecified or overlapping (C02.8, C02.9, C05.8, C05.9, C14.0, C14.2, C14.8), and larynx (C32.0-C32.3, C32.8, C32.9). Among the 2237 cases of HNC, 2161 (96.6\%) were squamous cell carcinomas and only 76 (3.4\%) presented other histological types (mainly unspecified carcinomas, adenocarcinomas, and other specified carcinomas). Of the 76 cases with other histological types, only one was exposed to leather dust; therefore, analysis was restricted to squamous cell carcinomas $(n=2161)$ and all controls $(n=3555)$. 


\section{Coding of job titles}

All jobs held for at least 1 month during the working life of the subjects were coded according to the International Standard Classification of Occupations (ISCO, 1968) [28] for occupations, and to the French Nomenclature of Activities (NAF, 2008) [29] for industries.

\section{Assessment of occupational exposure to leather dust}

Occupational exposure to leather dust was first assessed using a job-exposure matrix (JEM) for inhalable leather dust (particles < $100 \mu \mathrm{m}$ ) [30]. For each combination of ISCO and NAF codes, the JEM provided two indices: the probability of exposure (the percentage of exposed workers), and level of exposure. Then, using lifetime occupational history and indices of exposure provided by the JEM, the following exposure variables were computed: ever exposure to leather dust ("ever" defined as having worked in at least one job with a non-zero probability of exposure), maximum probability of exposure, maximum level of exposure, cumulative duration of exposure, and cumulative exposure index (CEI). The maximum probability and level of exposure were the highest probability and level measured over the entire occupational history of each subject. The cumulative duration of exposure was calculated by summing the periods in which the subject was exposed. CEI was estimated by the sum of the multiplication of the weighted duration, probability, and level of exposure on the entire professional life (see Additional file 1: Table S1).

For each job period involving leather work (shoemaking, and manufacture of leather clothes and other leather goods), a specific questionnaire was administered only to subjects that filled out a complete general questionnaire; it included questions about the materials handled, tasks performed, and exposure to several types of glues. Information from this specific questionnaire was analyzed in addition to the exposure assessment with the JEM.

\section{Statistical analysis}

Unconditional multivariable logistic regression was used to estimate odds ratios (ORs) and corresponding 95\% confidence intervals $(95 \% \mathrm{CI})$ of $\mathrm{HNC}$ associated with occupational exposure to leather dust. ORs were also estimated for each cancer subsite using multinomial (polytomous) logistic regression. All ORs were adjusted for age ( $<51,51-58,59-65$, and $\geq 66$ years), sex, area of residence (10 geographical areas), SES (assessed by the longest held occupation), tobacco smoking status (never; former: cessation $\geq 2$ years at the interview for controls, or at diagnosis for cases; current), tobacco consumption in pack-years (never, < 7, 7-16, 17-29, > 29), and alcohol drinking in glass-years (never, $<9,9-46,47-118,>118$ ). Categories for tobacco and alcohol consumption were based on the distribution of exposed controls, with quartiles used as cutoff points. Maximum probability and maximum level of exposure to leather dust were categorized as following: 0 (not exposed), $1-50,>50 \%$; and 0 (not exposed), $1-2.9 \mathrm{mg} / \mathrm{m}^{3}, \geq 3 \mathrm{mg} / \mathrm{m}^{3}$, respectively. Categories for the duration of exposure to leather dust and the CEI were based on the distribution of exposed controls, with medians used as cutoff points. Dose-response relationships between each variable of exposure to leather dust and $\mathrm{HNC}$ risk were explored using tests for linear trends by modelling the median of each category as a continuous variable. Analyses were also stratified on sex, and alcohol and tobacco status. Interactions between exposure to leather dust and sex, tobacco smoking, or alcohol drinking were tested using the test of maximum likelihood.

In addition, we performed analyses taking into account a lag time of 10 years by excluding exposure occurring 10 years before the diagnosis of cancer for cases, or the date of the interview for controls. Analyses by age at first exposure, time since first exposure and time since last exposure were also performed.

All tests were two-sided and a $p$ value $\leq 0.05$ was the threshold for statistical significance. Analyses were performed using the STATA software, version 12.1 (StataCorp, Texas, USA).

\section{Results}

The main characteristics of the subjects included in the analysis are presented in Table 1 . Cases were slightly younger than controls (average age: 57.8 vs. 58.5 years). Men represented more than two thirds of both cases and controls. The control group generally had a higher SES compared to cases $(p<0.0001)$. As expected, cases were more frequently current smokers and consumed more tobacco and alcohol than controls $(p<0.0001)$. Cancers of the oral cavity, oropharynx, hypopharynx, oral cavity/pharynx unspecified, and larynx represented $20.5,30.5,18.7,6.8$, and $23.5 \%$, respectively, of all squamous cell carcinomas included in the present study.

Fifty-seven cases (2.6\%) and 75 controls (2.2\%) held at least one job entailing exposure to leather dust (Table 2). Exposure status, maximum probability of exposure, and maximal level of exposure to leather dust did not differ significantly between cases and controls $(p=0.21,0.38$, and 0.16 , respectively). Nevertheless, the mean of cumulative duration of exposure among exposed cases was significantly lower than that of exposed controls (5.9 vs. 9.9 years; $p=0.008$ ). In addition, the mean of CEI was not significantly lower among exposed cases than that of exposed controls $\left(12.3 \mathrm{mg} / \mathrm{m}^{3}\right.$-years vs. $27.2 \mathrm{mg} /$ $\mathrm{m}^{3}$-years; $p=0.06$ ).

"Ever" exposure to leather dust was not associated with the risk of $\mathrm{HNC}$, overall and by subsite (Table 2). 
Table 1 Main characteristics of subjects included in the analysis and cancer subsites

\begin{tabular}{|c|c|c|c|c|c|}
\hline & \multicolumn{2}{|c|}{ Cases $(n=2161)$} & \multicolumn{2}{|c|}{ Controls $(n=3555)$} & \multirow{2}{*}{$\begin{array}{l}p \text {-value of } \\
\text { chi } 2 \text { test }\end{array}$} \\
\hline & $n$ & $\%$ & $\mathrm{n}$ & $\%$ & \\
\hline Age at interview (years, quartiles) & & & & & 0.003 \\
\hline Mean (SD) & \multicolumn{2}{|c|}{$57.8(8.6)$} & \multicolumn{2}{|c|}{$58.5(10.2)$} & \\
\hline$<51$ & 467 & 21.6 & 899 & 25.3 & \\
\hline $51-60$ & 767 & 35.5 & 812 & 22.8 & \\
\hline $59-65$ & 508 & 23.5 & 801 & 22.5 & \\
\hline$\geq 66$ & 419 & 19.4 & 1043 & 29.3 & \\
\hline \multicolumn{5}{|l|}{ Sex } & $<0.0001$ \\
\hline Male & 1862 & 86.2 & 2780 & 78.2 & \\
\hline Female & 299 & 13.8 & 775 & 21.8 & \\
\hline \multicolumn{5}{|l|}{ Area of residence } & $<0.0001$ \\
\hline Bas-Rhin & 232 & 10.7 & 469 & 13.2 & \\
\hline Calvados & 210 & 9.7 & 462 & 13.0 & \\
\hline Doubs, Territoire de Belfort & 47 & 2.2 & 143 & 4.0 & \\
\hline Hérault & 227 & 10.5 & 450 & 12.7 & \\
\hline Isère & 250 & 11.6 & 501 & 14.1 & \\
\hline Loire Atlantique & 359 & 16.6 & 404 & 11.4 & \\
\hline Manche & 238 & 11.0 & 312 & 8.8 & \\
\hline Haut-Rhin & 39 & 1.8 & 118 & 3.3 & \\
\hline Somme & 394 & 18.3 & 499 & 14.0 & \\
\hline Vendée & 165 & 7.6 & 197 & 5.5 & \\
\hline \multicolumn{5}{|l|}{ Socioeconomic status (the longest held job) } & $<0.0001$ \\
\hline Managers & 134 & 6.2 & 618 & 17.4 & \\
\hline Farmers & 51 & 2.4 & 197 & 5.5 & \\
\hline Self-employed workers & 136 & 6.3 & 177 & 4.9 & \\
\hline Intermediate white-collar workers & 218 & 10.1 & 695 & 19.5 & \\
\hline Office and sales employees & 341 & 15.8 & 672 & 18.9 & \\
\hline Blue-collar workers & 1241 & 57.4 & 1178 & 33.1 & \\
\hline \multicolumn{5}{|l|}{ Tobacco smoking status } & $<0.0001$ \\
\hline Never smokers & 110 & 5.1 & 1262 & 35.5 & \\
\hline Former smokers ${ }^{a}$ & 589 & 27.3 & 1461 & 40.1 & \\
\hline Current smokers & 1452 & 67.2 & 820 & 23.1 & \\
\hline \multicolumn{5}{|l|}{ Tobacco-smoking (pack-years, quartiles) } & $<0.0001$ \\
\hline Mean (SD) & \multicolumn{2}{|c|}{$38.3(25.2)$} & \multicolumn{2}{|c|}{$13.2(18.4)$} & \\
\hline Never smokers & 110 & 5.1 & 1262 & 35.5 & \\
\hline$<7$ & 94 & 4.3 & 581 & 16.6 & \\
\hline $7-16$ & 174 & 8.1 & 566 & 16.1 & \\
\hline $17-29$ & 376 & 17.4 & 535 & 15.2 & \\
\hline$>29$ & 1361 & 62.9 & 566 & 16.1 & \\
\hline \multicolumn{3}{|l|}{ Alcohol drinking (glass-years, quartiles) } & & & $<0.0001$ \\
\hline Mean (SD) & \multicolumn{2}{|c|}{$213.1(233.6)$} & \multicolumn{2}{|c|}{$78.3(120.1)$} & \\
\hline Never drinkers & 103 & 4.8 & 306 & 8.6 & \\
\hline$<9$ & 149 & 6.9 & 803 & 22.6 & \\
\hline $9-46$ & 174 & 8.1 & 806 & 22.7 & \\
\hline
\end{tabular}


Table 1 Main characteristics of subjects included in the analysis and cancer subsites (Continued)

\begin{tabular}{|c|c|c|c|c|c|}
\hline & \multicolumn{2}{|c|}{ Cases $(n=2161)$} & \multicolumn{2}{|c|}{ Controls $(n=3555)$} & \multirow{2}{*}{$\begin{array}{l}p \text {-value of } \\
\text { chi } 2 \text { test }\end{array}$} \\
\hline & $\bar{n}$ & $\%$ & $\bar{n}$ & $\%$ & \\
\hline $47-118$ & 378 & 17.5 & 804 & 22.6 & \\
\hline$>118$ & 1273 & 58.9 & 802 & 22.6 & \\
\hline \multicolumn{6}{|l|}{ Cancer subsites $^{\mathrm{b}}$} \\
\hline Oral cavity & 444 & 20.5 & - & - & \\
\hline Oropharynx & 658 & 30.5 & - & - & \\
\hline Hypopharynx & 405 & 18.7 & - & - & \\
\hline Oral cavity/pharynx unspecified & 148 & 6.8 & - & - & \\
\hline Larynx & 506 & 23.5 & - & - & \\
\hline
\end{tabular}

${ }^{a}$ Former smokers were subjects who had stopped smoking at least two years before the interview (controls) or diagnosis (cases)

${ }^{b}$ Only squamous cell carcinomas were included in the study

No significant associations were found regarding the maximum probability of exposure, the maximum level of exposure and the cumulative duration of exposure, either for the HNC globally or for its subsites. Generally, the ORs were higher for the lower category of exposure. Concerning the CEI, borderline significant and significant associations were found for oral cavity/pharynx unspecified $(\mathrm{OR}=3.04,95 \%$ CI $0.97-9.54 ; p=0.09)$ and larynx (OR $=2.26,95 \%$ CI 1.07-4.76), but only in the lowest category of exposure. No dose-response patterns were observed.

Additional analyses conducted in those most exposed to leather dust (e.g., maximum probability $>90 \%$, maximum level $>7 \mathrm{mg} / \mathrm{m}^{3}$, cumulative duration $>75 \mathrm{th}$ percentile of controls, and CEI > 90th percentile of controls) showed no associations with $\mathrm{HNC}(\mathrm{OR}=0.73,95 \%$ CI $0.37-1.41 ; 1.36,95 \%$ CI $0.54-3.43 ; 0.29,95 \%$ CI $0.02-5.74$; and $0.87,95 \%$ CI $0.05-13.55$, respectively). When all parameters were combined to define a category of subjects presenting the highest exposure profile, there were not enough subjects to conduct further analyses ( 0 cases and 2 controls).

Only 2 cases and 5 controls had jobs entailing exposure to leather dust, which ended less than 10 years before the diagnosis or interview; the results changed only marginally when taking into account a 10-year lag period (for example, for "ever" exposure to leather dust $\mathrm{OR}=1.05$, 95\% CI $0.67-1.56$ for head and neck overall, and $1.47,95 \%$ CI $0.78-2.76$ for larynx). No associations were observed regarding time since first exposure, time since last exposure, and age at first exposure $(\mathrm{OR}=0.99$, 95\% CI $0.98-1.01 ; 0.96$, 95\% CI $0.75-1.22$; and 1.0, 95\% $\mathrm{CI}=0.95-1.04$, respectively).

The analysis stratified by sex revealed that $2.2 \%$ of men and $2.9 \%$ of women were exposed to leather dust. Even if the ORs were slightly higher among men than among women, no significant differences were observed (see Additional file 1: Table S2). The analysis stratified by tobacco and alcohol consumption revealed that $2.4 \%$ of ever smokers, $2.2 \%$ of never smokers, $2.3 \%$ of ever drinkers, and $2.2 \%$ of never drinkers were exposed to leather dust. Although ORs were slightly higher for smokers and drinkers compared to non-consumers, no significant associations were observed (see Additional file 1: Table S3 and Table S4). Interactions between gender, tobacco smoking, alcohol consumption and occupational exposure to leather dust were not significant.

Regarding the analyses performed on the data from the questionnaire on leather work, 24 cases $(1.2 \%)$ and 31 controls $(0.9 \%)$ filled out at least one specific questionnaire (Table 3). Compared to subjects that did not answer the questionnaire, there was no increased risk of $\mathrm{HNC}$ in subjects that did answer the questionnaire (OR $=1.15,95 \%$ CI $0.57-2.31$ ).

Slightly elevated (although non-significant) risks of $\mathrm{HNC}$ were observed for exposure to soft leather (OR = 1.33, 95\% CI 0.61-2.92), crepe rubber $(\mathrm{OR}=1.93,95 \%$ CI $0.57-6.54)$, and synthetic leather $(\mathrm{OR}=1.44,95 \% \mathrm{CI}$ 0.53-3.86). Exposure to other materials (i.e. wood, cork, cardboard, twine, or pitch) was associated with a significantly elevated risk of $\mathrm{HNC}(\mathrm{OR}=18.75,95 \%$ CI 1.77 197.89), although this was based on only 8 exposed subjects ( 7 cases and 1 control).

Regarding the risk of $\mathrm{HNC}$ associated with the tasks performed, non-significantly increased risks were observed for scouring, roughing, grinding, trimming, and buffing of leather (OR $=1.49,95 \%$ CI $0.56-3.92)$, dyeing $(\mathrm{OR}=3.22$, 95\% CI $0.77-13.32)$, and other tasks (shoes varnishing, polishing, or brushing) $(\mathrm{OR}=8.08,95 \% \mathrm{CI}$ 0.66-98.21).

Exposure to neoprene glues, and strong or animal skin glues was associated with non-significantly elevated risks of $\mathrm{HNC}(\mathrm{OR}=1.52,95 \% \mathrm{CI} 0.68-3.39$, and $\mathrm{OR}=1.60$, 95\% CI 0.70-3.65, respectively).

\section{Discussion}

The present study explored occupational exposure to leather dust in relation to HNC through the ICARE 


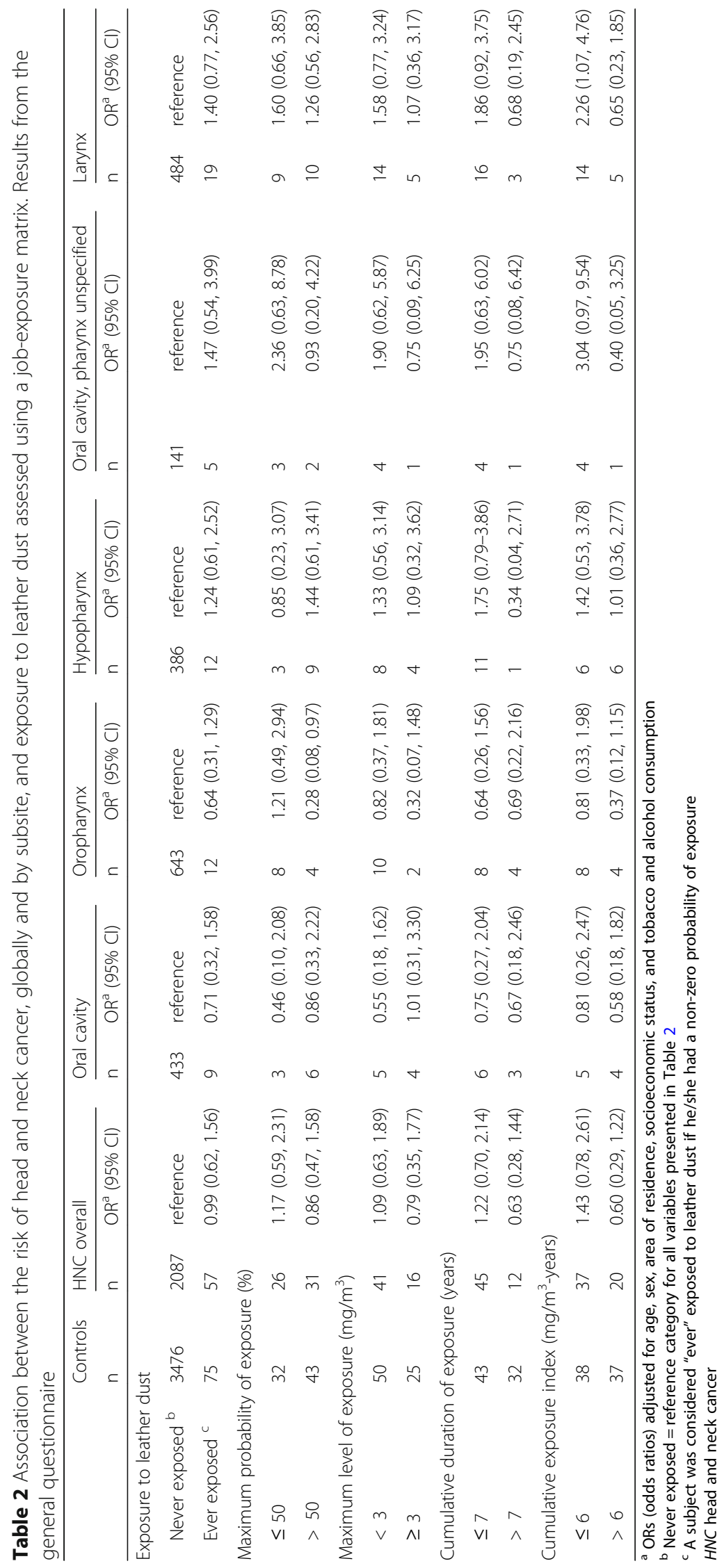


Table 3 Associations between the risk of head and neck cancer and materials handled, tasks performed, and glues used. Results from the specific questionnaire on leather work

\begin{tabular}{|c|c|c|c|c|c|}
\hline & \multicolumn{2}{|c|}{ Cases $(n=1926)$} & \multicolumn{2}{|c|}{ Controls $(n=3481)$} & \multirow[t]{2}{*}{$\mathrm{OR}^{\mathrm{a}}(95 \% \mathrm{Cl})$} \\
\hline & $\mathrm{n}$ & $\%$ & $\mathrm{n}$ & $\%$ & \\
\hline \multicolumn{6}{|c|}{ Held at least one job exposed to leather dust and filled out at least one specific questionnaire } \\
\hline No ${ }^{b}$ & 1902 & 98.8 & 3450 & 99.1 & reference \\
\hline Yes & 24 & 1.2 & 31 & 0.9 & $1.15(0.57,2.31)$ \\
\hline \multicolumn{6}{|c|}{ Materials handled } \\
\hline \multicolumn{6}{|c|}{ Exposure to soft leather } \\
\hline Never & 2 & 0.1 & 5 & 0.1 & $0.95(0.16,5.63)$ \\
\hline Ever & 19 & 0.9 & 24 & 0.6 & $1.33(0.61,2.92)$ \\
\hline \multicolumn{6}{|c|}{ Exposure to thick leather } \\
\hline Never & 7 & 0.3 & 9 & 0.2 & $1.86(0.55,6.25)$ \\
\hline Ever & 14 & 0.7 & 21 & 0.6 & $0.86(0.36,2.06)$ \\
\hline \multicolumn{6}{|c|}{ Exposure to crepe rubber } \\
\hline Never & 9 & 0.4 & 21 & 0.6 & $0.77(0.28,2.05)$ \\
\hline Ever & 10 & 0.5 & 7 & 0.2 & $1.93(0.57,6.54)$ \\
\hline \multicolumn{6}{|c|}{ Exposure to synthetic leather } \\
\hline Never & 12 & 0.6 & 14 & 0.4 & $1.14(0.41,3.14)$ \\
\hline Ever & 10 & 0.5 & 15 & 0.4 & $1.44(0.53,3.86)$ \\
\hline \multicolumn{6}{|c|}{ Exposure to textile materials } \\
\hline Never & 17 & 0.8 & 18 & 0.5 & $1.69(0.70,4.03)$ \\
\hline Ever & 6 & 0.3 & 11 & 0.3 & $0.75(0.21,2.56)$ \\
\hline \multicolumn{6}{|c|}{ Exposure to other materials ${ }^{c}$} \\
\hline Never & 15 & 0.7 & 25 & 0.7 & $0.88(0.39,2.01)$ \\
\hline Ever & 7 & 0.3 & 1 & $<0.1$ & $18.75(1.77,197.89)$ \\
\hline \multicolumn{6}{|c|}{ Tasks performed } \\
\hline \multicolumn{6}{|c|}{ Cutting of leather } \\
\hline Never & 5 & 0.2 & 9 & 0.2 & $1.08(0.25,4.51)$ \\
\hline Ever & 18 & 0.9 & 21 & 0.6 & $1.17(0.52,2.63)$ \\
\hline \multicolumn{6}{|c|}{ Cutting of other materials } \\
\hline Never & 10 & 0.5 & 14 & 0.4 & $1.61(0.53,4.88)$ \\
\hline Ever & 12 & 0.6 & 16 & 0.4 & $1.03(0.41,2.57)$ \\
\hline \multicolumn{6}{|c|}{ Scouring, roughing, grinding, trimming, buffing of leather } \\
\hline Never & 9 & 0.4 & 15 & 0.4 & $1.14(0.39,3.30)$ \\
\hline Ever & 13 & 0.6 & 14 & 0.4 & $1.49(0.56,3.92)$ \\
\hline \multicolumn{6}{|l|}{ Gluing } \\
\hline Never & 6 & 0.3 & 8 & 0.2 & $2.88(0.74,11.2)$ \\
\hline Ever & 18 & 0.9 & 22 & 0.6 & $1.02(0.47,2.23)$ \\
\hline \multicolumn{6}{|l|}{ Sewing } \\
\hline Never & 7 & 0.3 & 8 & 0.2 & $0.80(0.22,2.85)$ \\
\hline Ever & 17 & 0.8 & 23 & 0.6 & $1.34(0.59,3.05)$ \\
\hline \multicolumn{6}{|l|}{ Dyeing } \\
\hline Never & 14 & 0.7 & 24 & 0.6 & $0.81(0.34,1.91)$ \\
\hline Ever & 9 & 0.4 & 6 & 0.1 & $3.22(0.77,13.32)$ \\
\hline
\end{tabular}

Injection of plastic materials 
Table 3 Associations between the risk of head and neck cancer and materials handled, tasks performed, and glues used. Results from the specific questionnaire on leather work (Continued)

\begin{tabular}{|c|c|c|c|c|c|}
\hline & \multicolumn{2}{|c|}{ Cases $(n=1926)$} & \multicolumn{2}{|c|}{ Controls $(n=3481)$} & \multirow[t]{2}{*}{$\mathrm{OR}^{\mathrm{a}}(95 \% \mathrm{Cl})$} \\
\hline & $\bar{n}$ & $\%$ & $\mathrm{n}$ & $\%$ & \\
\hline Never & 19 & 0.9 & 26 & 0.7 & $1.39(0.64,3.02)$ \\
\hline Ever & 3 & 0.1 & 3 & $<0.1$ & $0.84(0.12,5.95)$ \\
\hline \multicolumn{6}{|c|}{ Other tasks ${ }^{d}$} \\
\hline Never & 19 & & 24 & & $1.17(0.54,2.51)$ \\
\hline Ever & 2 & 0.1 & 2 & 0.1 & $8.08(0.66,98.21)$ \\
\hline \multicolumn{6}{|l|}{ Glues used } \\
\hline \multicolumn{6}{|c|}{ Neoprene glues } \\
\hline Never & 6 & 0.3 & 7 & 0.2 & $0.55(0.14,2.05)$ \\
\hline Ever & 18 & 0.9 & 24 & 0.6 & $1.52(0.68,3.39)$ \\
\hline \multicolumn{6}{|c|}{ Solvent-based / rubber-based adhesives } \\
\hline Never & 6 & 0.3 & 7 & 0.2 & $1.03(0.27,3.92)$ \\
\hline Ever & 18 & 0.9 & 24 & 0.6 & $1.20(0.53,2.71)$ \\
\hline \multicolumn{6}{|c|}{ Strong glues/animal skin glues } \\
\hline Never & 6 & 0.3 & 10 & 0.2 & $0.54(0.15,1.94)$ \\
\hline Ever & 18 & 0.9 & 21 & 0.6 & $1.60(0.70,3.65)$ \\
\hline \multicolumn{6}{|c|}{ Polyurethane glues } \\
\hline Never & 10 & 0.5 & 7 & 0.2 & $1.87(0.54,6.49)$ \\
\hline Ever & 14 & 0.7 & 24 & 0.6 & $0.92(0.39,2.16)$ \\
\hline \multicolumn{6}{|c|}{ Other glues } \\
\hline Never & 6 & 0.3 & 9 & 0.2 & $0.99(0.28,3.43)$ \\
\hline Ever & 17 & 0.8 & 22 & 0.6 & $1.21(0.52,2.82)$ \\
\hline
\end{tabular}

${ }^{a}$ ORs (odds ratios) adjusted for age, sex, area of residence, socioeconomic status, and tobacco and alcohol consumption

${ }^{b}$ Reference category for all analyses on materials handled, tasks performed, and glues used was the category of subjects that never held a job entailing leather dust exposure and that did not filled out (a) specific leather questionnaire(s)

c Wood, cork, cardboard, twine, pitch

d Shoes varnishing, polishing and brushing

study, a large population-based case-control study in France. Exposure was assessed using a JEM and a specific questionnaire, making it possible to analyze the type of materials, tasks performed, and the concomitant exposure to several glues. Significant or borderline associations were found in lower exposure categories of CEI for the subsites: larynx, and oral cavity/pharynx unspecified. Exposure to some materials (soft leather, crepe rubber, and synthetic leather), tasks (scouring, roughing, grinding, trimming and buffing of leather, and dyeing), and glues (neoprene glues, and strong or animal skin glues) was associated with elevated, although non-significant, risks of HNC. No dose-response relationships were observed, neither in the JEM analyses nor in the specific questionnaire analyses. The majority of subjects had short-term and distant exposure to leather dust (generally, they were young apprentices, performing multiple tasks). We were unable to analyze associations for exclusive exposure to materials or glues, or exclusive tasks, because the majority of subjects had multiple occupational exposures and tasks throughout their employment.

While IARC considers leather dust to be causally related to sinonasal cancers, the literature remains sparse and inconsistent for other HNC sites. Two cohort studies in shoe-manufacturing workers [31, 32] observed slightly more cases of death by oral and pharyngeal cancer than expected, contrary to two others that observed either slightly fewer cases than expected [33] or no excess risk [34]. A census-based study observed a significantly increased risk of oral and pharyngeal cancer among shoe makers/cobblers, based only on two cases [21]. The results of case-control studies are also inconsistent. One study [23] observed non-significantly increased risks for both oral cavity and pharyngeal squamous cell carcinomas associated with exposure to leather dust, while another [25] found no association with hypopharynx cancers. A pooled analysis of four European studies found a non-significantly increased risk of squamous cell carcinomas of the hypopharynx 
and larynx group together among shoe finishers, with no association with duration of employment [19]. Concerning laryngeal cancer alone, cohort studies did not find excess risks in shoe-manufacturing workers [31-33, 35]. Two case-control studies [16, 23] observed an increased risk of laryngeal carcinoma associated with exposure to leather dust, while one study [25] did not find any association. An American case-control study observed significant risks for head and neck overall, and pharyngeal squamous cell carcinomas increasing with each decade of exposure to leather dust. Although not significant, point estimates were also elevated for cancers of the oral cavity and larynx for each successive decade of exposure [18]. In our study, non-significantly elevated risks for squamous cell carcinomas of hypopharynx, oral cavity/ pharynx not specified, and larynx were associated with exposure to leather dust, but only among subjects with lower or shorter exposures; no associations were observed for cancers of the oral cavity or pharynx. Nevertheless, the average duration of exposure among cases reported in the study of Langevin et al. [18] was well above that observed in the present study ( 24 years vs. 5.9 years).

Two Finnish studies [21, 24] analyzed the risk for cancers of the oral cavity/pharynx, and larynx associated with exposure to leather dust estimated by the matrix FINJEM. The CEI was categorized in four categories: none, low, medium, and high exposure. No statistically significant associations were observed, although ORs were higher for the medium category $(5-19 \mathrm{mg} /$ $\mathrm{m}^{3}$-years $)$ in the first study and for the low category $(<5$ $\mathrm{mg} / \mathrm{m}^{3}$-years) in the second one. Similarly, we found elevated risk of cancer of the larynx or oral cavity/pharynx (unspecified) associated with a CEI $<6 \mathrm{mg} / \mathrm{m}^{3}$-years, but not for higher exposure. This, in addition to the lack of a dose-response pattern, indicates that our study does not provide sufficient evidence for an association between $\mathrm{HNC}$ and exposure to leather dust.

The reliability of the present study may be considered as good. Indeed, this work provided results from one of the largest multicenter population-based case-control studies ever conducted on occupational risk factors for HNC. The large sample size allowed analyses by specific cancer sites. The collaboration with the French network of cancer registries allowed for recruitment of almost all cases with HNC in the covered geographical areas. The randomly selected control group showed a distribution of socioeconomic characteristics, and lifelong occupational exposure to leather dust comparable to that of the general population $(2.2 \%$ in study controls vs. $2.4 \%$ in the French population [30]). Participation rates were satisfactory for the design of the study $(80.6 \%$ for controls, and $82.5 \%$ for cases). Selection bias was therefore limited.
The specific questionnaire on leather work represented a strength of our study. The analysis was an opportunity to explore tasks such as cutting, scouring, roughing, grinding, trimming, and buffing, which are likely to expose the subject to greatest volume of leather dust. Handling of leather in boot and shoe manufacture may also entail exposure to chemicals used in the tanning and finishing processes, and other chemicals such as dyes, adhesives and solvents, for which there is evidence of carcinogenicity in humans [15]. A Russian mortality study on shoe-manufacturing workers found high leather dust concentrations $\left(6.5-12 \mathrm{mg} / \mathrm{m}^{3}\right)$ in the following production departments: cutting, fitting, lasting and making, and finishing [36]. In this study, leather dust was present along with solvents and chloroprene. In a Finnish study on shoe repairers, the time-weighted average concentrations of dust ranged between 0.07 and $1.0 \mathrm{mg} / \mathrm{m}^{3}$ near the roughing, scouring, and finishing machines; dust samples contained leather, polymers, finishing materials, and chromium [37]. In 1993, an American study on shoe workers [38], updated in 2006 [34], did not find any association between the cancers of oral cavity and pharynx and exposure to solvents, mostly toluene. Also, neither leather dust nor solvent exposure were associated with the risk of laryngeal cancer in a pooled analysis of two updated shoe-manufacturing cohorts [35]. In our study, non-significantly elevated risks were observed for some materials, tasks, and glues. Nevertheless, detailed analyses were difficult to perform as few workers described precisely the duration of their daily tasks and co-exposures. The small sample size in some categories reduced the statistical power required for robust associations.

Our study has some limitations. Recall bias may not be excluded, especially among those potentially underreporting their occupational history due to fatigue. Cases reported an average number of jobs slightly lower than that of the controls ( 4.1 vs. 4.4 [complete questionnaire]; 2.7 vs. 3.0 [shorter version]). In addition, cases more frequently answered shorter questionnaires than the controls (10.6\% vs. $2.1 \%)$. Consequently, information about tasks performed and materials handled were less frequently reported by the cases due to the fact that they did not fill out the specific questionnaire on leather work. Although occupations and industries were self-reported, it is unlikely that differential reporting bias occurred because occupational exposure to leather dust is not a widely known risk factor for HNC.

Data were collected by trained interviewers using standardized questionnaires, which limited eventual differential misclassification bias. Coding occupation and industry is difficult, and often not reproducible. Therefore, coders were well-trained and blinded to case-control status. If coding errors occurred, they were probably not differential between cases and controls. 
Residual confounding may not be excluded. Special attention was paid to adjustment for tobacco and alcohol consumption, and SES. Additional adjustments for body mass index, education level, exposure to asbestos and family history of HNC in first-degree relatives were made, but they did not substantially change the results. In addition, data on HPV infection and diet were not available, but it is unlikely that they would explain our results.

The exposure assessment was not based on direct measurement collected on an individual level, but was estimated through a JEM, based on job-specific averages, which does not take into account the heterogeneity of tasks within the same job title. Conversely, the JEM assigns exposure in a reproducible and automatic way, regardless of the subject status (case or control). Consequently, a non-differential misclassification bias may have occurred, which results generally in a biased estimation of the OR towards the null for dichotomous exposures [39]. However, in certain non-differential misclassification conditions with polychotomous exposure variables, estimates of ORs for categories at intermediate level can be biased away from the null [39], which could partly explain the elevated risks observed only in lower categories of exposure in the present study.

In conclusion, results from this large French population-based case-control study did not provide enough evidence in favor of a role of occupational exposure to leather dust in HNC. Further larger studies are necessary to understanding of the risks of performing specific tasks while being exposed to other agents in the leather industry.

\section{Additional file}

Additional file 1: Table S1. Formula and weight for calculating the cumulative exposure index (CEI) to leather dust. Table S2. Odds ratios for head and neck cancer associated with occupational exposure to leather dust, stratified by sex. Table S3. Odds ratios for head and neck cancer associated with occupational exposure to leather dust, stratified by tobacco smoking status. Table S4. Odds ratios for head and neck cancer associated with occupational exposure to leather dust, stratified by alcohol drinking status. (DOCX $60 \mathrm{~kb}$ )

\section{Abbreviations}

CEl: Cumulative exposure index; HNC: Head and neck cancers; HPV: Human papilloma virus; IARC: International Agency for Research on Cancer; ICD-O3: International Classification of Diseases for Oncology, 3rd edition;

ISCO: International Standard Classification of Occupations; JEM: Job exposure matrix; NAF: French Nomenclature of Activities; SES: Socioeconomic status

\section{Acknowledgements}

The authors thank all members of the MatGéné working group from Santé Publique France for providing the job-exposure matrix of leather work. Members of ICARE Study Group: Anne-Valérie Guizard (Registre des cancers du Calvados, France); Arlette Danzon, Anne-Sophie Woronoff (Registre des cancers du Doubs, France); Michel Velten (Registre des cancers du Bas-Rhin, France); Antoine Buemi, Émilie Marrer (Registre des cancers du Haut-Rhin, France); Brigitte Trétarre (Registre des cancers de l'Hérault, France); Marc
Colonna, Patricia Delafosse (Registre des cancers de l'sère, France); Paolo Bercelli, Florence Molinié (Registre des cancers de Loire-Atlantique-Vendée, France); Simona Bara (Registre des cancers de la Manche, France); Bénédicte Lapotre-Ledoux, Nicole Raverdy (Registre des cancers de la Somme, France); Sylvie Cénée, Oumar Gaye, Florence Guida, Farida Lamkarkach, Loredana Radoï, Marie Sanchez, Isabelle Stücker (INSERM, Centre for research in Epidemiology and Population Health (CESP), U1018, Environmental Epidemiology of Cancer Team, Villejuif, France); Matthieu Carton, Diane Cyr, Annie Schmaus (Inserm Epidemiologic Cohorts Unit-UMS 011 INSERM-UVSQ, Villejuif, France); Joëlle Févotte (University Lyon 1, UMRESTTE, Lyon, France); Corinne Pilorget (French Public Health Agency, Department of Occupational Health, Saint Maurice, France); Gwenn Menvielle (Sorbonne Universités, UPMC Univ Paris 06, INSERM, IPLESP UMRS 1136, Paris, France); Danièle Luce (INSERM U 1085-IRSET, Pointe-à-Pitre, France).

\section{Funding}

The ICARE study was funded by the French National Research Agency (ANR): French National Cancer Institute (INCA); French Agency for Food, Environmental and Occupational Health and Safety (ANSES); French Institute for Public Health Surveillance (InVS); Fondation pour la Recherche Médicale (FRM); Fondation de France; Association pour la Recherche sur le Cancer (ARC); Ministry of Labour (Direction Générale du Travail); Ministry of Health (Direction Générale de la Santé).

\section{Availability of data and materials}

The data that support the findings of this study are available from the corresponding author upon reasonable request.

\section{Authors' contributions}

$L R$ and $D L$ designed the current study, conducted the analyses and drafted the manuscript; FS, MM, CB and GM contributed to the statistical analysis and interpretation of the results. PD contributed to data collection and quality control. DL and IS are the principal investigators of the ICARE study, conceived this study and coordinated the original collection of the data. All the authors critically reviewed and revised the manuscript, and approved the final version

\section{Ethics approval and consent to participate}

The study was approved by the Institutional Review Board of the French National Institute of Health and Medical Research (IRB-Inserm, no. 01-036), and by the French Data Protection Authority (CNIL no. 90120).

Each participant gave a written informed consent.

\section{Consent for publication}

Not applicable.

\section{Competing interests}

The authors declare that they have no competing interests.

\section{Publisher's Note}

Springer Nature remains neutral with regard to jurisdictional claims in published maps and institutional affiliations.

\footnotetext{
Author details

'Paris Sud, Paris Saclay University, UVSQ, CESP, INSERM U1018, Environmental Epidemiology of Cancer Team, Villejuif, France. ${ }^{2}$ Oral medicine and oral surgery department, University Paris Descartes, Faculty of Dental surgery, Paris, France. ${ }^{3}$ University Pierre et Marie Curie, Paris, France. ${ }^{4}$ Faculty of Medicine, University Paris Est Créteil, Créteil, France. ${ }^{5}$ Centre Hospitalier Intercommunal, Service des Pathologies Professionnelles et de I'Environnement, Créteil, France. ${ }^{6}$ Université de Rennes, Inserm, EHESP, Irset (Institut de Recherche en Santé, Environnement et Travail)-UMR_S 1085, Pointe-à-Pitre, France. 'Department of social epidemiology, INSERM, Sorbonne Université, Institut Pierre Louis d'Epidémiologie et de Santé Publique IPLESP, Paris, France. ${ }^{8}$ Isère Cancer Registry, CHU Grenoble-Alpes, Grenoble; FRANCIM Network, Toulouse, France.
} 
Received: 19 October 2018 Accepted: 20 March 2019 Published online: 29 March 2019

\section{References}

1. Ferlay J, Soerjomataram I, Ervik M, Dikshit R, Eser S, Mathers C, Rebelo M, Parkin DM, Forman D, Bray F. GLOBOCAN 2012: Estimated Cancer Incidence, Mortality and Prevalence Worldwide in 2012 v1.0. IARC CancerBase No. 11. Available from: http://publications.iarc.fr/Databases/larc-Cancerbases/ GLOBOCAN-2012-Estimated-Cancer-Incidence-Mortality-And-PrevalenceWorldwide-In-2012-V1.0-2012. Accessed 16 June 2017.

2. IARC Monographs on the Evaluation of Carcinogenic Risks to Humans. Tobacco smoke and involuntary smoking. Volume 83. Lyon, France: IARC; 2004.

3. IARC Monographs on the Evaluation of Carcinogenic Risks to Humans Alcohol consumption and ethyl carbamate, vol. 96. Lyon, France: IARC; 2010.

4. IARC Monographs on the Evaluation of Carcinogenic Risks to Humans. A Review of Human Carcinogens: Biological agents. Volume 100B. Lyon, France: IARC: 2012.

5. D'Souza G, Dempsey A. The role of HPV in head and neck cancer and review of the HPV vaccine. Prev Med. 2011:53(Suppl 1):S5-11.

6. Chuang SC, Jenab M, Heck JE, Bosetti C, Talamini R, Matsuo K, Castellsague X, Franceschi S, Herrero R, Winn DM, La Vecchia C, Morgenstern H, Zhang ZF, Levi F, Dal Maso L, Kelsey K, McClean MD, Vaughan T, Lazarus P, Muscat J, Ramroth H, Chen C, Schwartz SM, Eluf-Neto J, Hayes RB, Purdue M, Boccia S, Cadoni G, Zaridze D, Koifman S, Curado MP, Ahrens W, Benhamou S, Matos E, Lagiou P, Szeszenia-Dabrowska N, Olshan AF, Fernandez L, Menezes A, Agudo A, Daudt AW, Merletti F, Macfarlane GJ, Kjaerheim K, Mates D, Holcatova I, Schantz S, Yu GP, Simonato L, Brenner H, Mueller H, Conway DI, Thomson P, Fabianova E, Znaor A, Rudnai P, Healy CM, Ferro G, Brennan P, Boffetta P, Hashibe M. Diet and the risk of head and neck cancer: a pooled analysis in the INHANCE consortium. Cancer Causes Control. 2012;23(1):69-88.

7. Guha N, Boffetta P, Wunsch Filho V, Eluf Neto J, Shangina O, Zaridze D, Curado MP, Koifman S, Matos E, Menezes A, Szeszenia-Dabrowska N, Fernandez L, Mates D, Daudt AW, Lissowska J, Dikshit R, Brennan P. Oral health and risk of squamous cell carcinoma of the head and neck and esophagus: results of two multicentric case-control studies. Am J Epidemiol. 2007;166(10):1159-73.

8. Conway DI, McKinney PA, McMahon AD, Ahrens W, Schmeisser N, Benhamou S, Bouchardy C, Macfarlane GJ, Macfarlane TV, Lagiou P, Minaki P, Bencko V, Holcatova I, Merletti F, Richiardi L, Kjaerheim K, Agudo A, Castellsague X, Talamini R, Barzan L, Canova C, Simonato L, Lowry RJ, Znaor A, Healy CM, McCartan BE, Marron M, Hashibe M, Brennan P. Socioeconomic factors associated with risk of upper aerodigestive tract cancer in Europe. Eur J Cancer. 2010;46(3):588-98.

9. Conway DI, Petticrew M, Marlborough H, Berthiller J, Hashibe M, Macpherson LM. Socioeconomic inequalities and oral cancer risk: a systematic review and meta-analysis of case-control studies. Int J Cancer. 2008;122(12):2811-9.

10. Menvielle G, Luce D, Goldberg P, Leclerc A. Smoking, alcohol drinking, occupational exposures and social inequalities in hypopharyngeal and laryngeal cancer. Int J Epidemiol. 2004;33(4):799-806.

11. IARC Monographs on the Evaluation of Carcinogenic Risks to Humans. Occupational exposures to mists and Vapours from strong inorganic acids; and other industrial chemicals, vol. 54. Lyon, France: IARC; 1992.

12. Straif $K$, Benbrahim-Tallaa $L$, Baan $R$, Grosse $Y$, Secretan B, El Ghissassi $F$, Bouvard V, Guha N, Freeman C, Galichet L, Cogliano V. A review of human carcinogens--part C: metals, arsenic, dusts, and fibres. Lancet Oncol. 2009; 10(5):453-4

13. Paget-Bailly S, Cyr D, Luce D. Occupational exposures and cancer of the larynx-systematic review and meta-analysis. J Occup Environ Med. 2012; 54(1):71-84

14. Paget-Bailly S, Cyr D, Luce D. Occupational exposures to asbestos, polycyclic aromatic hydrocarbons and solvents, and cancers of the oral cavity and pharynx: a quantitative literature review. Int Arch Occup Environ Health. 2012;85(4):341-51.

15. IARC Monographs on the Evaluation of Carcinogenic Risks to Humans Arsenic, Metals, Fibres and dusts. Volume 100C. Lyon, France: IARC; 2012

16. Decoufle P. Cancer risks associated with employment in the leather and leather products industry. Arch Environ Health. 1979;34(1):33-7.
17. Andersen A, Barlow L, Engeland A, Kjaerheim K, Lynge E, Pukkala E. Workrelated cancer in the Nordic countries. Scand J Work Environ Health. 1999; 25(Suppl 2):1-116

18. Langevin SM, McClean MD, Michaud DS, Eliot M, Nelson HH, Kelsey KT. Occupational dust exposure and head and neck squamous cell carcinoma risk in a population-based case-control study conducted in the greater Boston area. Cancer Med. 2013;2(6):978-86.

19. Boffetta $P$, Richiardi $L$, Berrino F, Esteve J, Pisani $P$, Crosignani $P$, Raymond $L$, Zubiri L, Del Moral A, Lehmann W, Donato F, Terracini B, Tuyns A, Merletti F. Occupation and larynx and hypopharynx cancer: an international casecontrol study in France, Italy, Spain, and Switzerland. Cancer Causes Control. 2003;14(3):203-12

20. Ahrens W, Jockel KH, Patzak W, Elsner G. Alcohol, smoking, and occupational factors in cancer of the larynx: a case-control study. Am J Ind Med. 1991;20(4):477-93.

21. Tarvainen L, Kyyronen P, Kauppinen T, Pukkala E. Cancer of the mouth and pharynx, occupation and exposure to chemical agents in Finland (in 197195). Int J Cancer. 2008;123(3):653-9.

22. Coggon D, Pannett B, Osmond C, Acheson ED. A survey of cancer and occupation in young and middle aged men. I. Cancers of the respiratory tract. Br J Ind Med. 1986;43(5):332-8.

23. Gustavsson $\mathrm{P}$, Jakobsson $\mathrm{R}$, Johansson $\mathrm{H}_{\text {, Lewin }} \mathrm{F}$, Norell S, Rutkvist LE. Occupational exposures and squamous cell carcinoma of the oral cavity, pharynx, larynx, and oesophagus: a case-control study in Sweden. Occup Environ Med. 1998;55(6):393-400

24. Laakkonen A, Kyyronen P, Kauppinen T, Pukkala El. Occupational exposure to eight organic dusts and respiratory cancer among Finns. Occup Environ Med. 2006;63(11):726-33.

25. Laforest L, Luce D, Goldberg P, Begin D, Gerin M, Demers PA, Brugere J, Leclerc A. Laryngeal and hypopharyngeal cancers and occupational exposure to formaldehyde and various dusts: a case-control study in France. Occup Environ Med. 2000;57(11):767-73.

26. Luce D, Stucker I. Investigation of occupational and environmental causes of respiratory cancers (ICARE): a multicenter, population-based case-control study in France. BMC Public Health. 2011;11:928.

27. Word Health Organization. International classification of diseases for oncology. 3rd ed. Geneva: World Health Organization; 2000.

28. International Labour Office. International standard classification of occupations. Geneva: International Labour Office; 1968.

29. Institut National de la Statistique et des Etudes Economiques. Nomenclature d'activités et de produits française, NAF. Paris, France: Institut National de la Statistique et des Etudes Economiques; 1999.

30. Fevotte J, Dananche B, Delabre L, Ducamp S, Garras L, Houot M, Luce D, Orlowski E, Pilorget C, Lacourt A, Brochard P, Goldberg M, Imbernon E. Matgene: a program to develop job-exposure matrices in the general population in France. Ann Occup Hyg. 2011;55(8):865-78.

31. Decoufle $P$, Walrath J. Proportionate mortality among US shoeworkers, 1966-1977. Am J Ind Med. 1983:4(4):523-32

32. Walrath J, Decoufle $P$, Thomas TL. Mortality among workers in a shoe manufacturing company. Am J Ind Med. 1987;12(5):615-23.

33. Garabrant DH, Wegman DH. Cancer mortality among shoe and leather workers in Massachusetts. Am J Ind Med. 1984:5(4):303-14.

34. Lehman EJ, Hein MJ. Mortality of workers employed in shoe manufacturing: an update. Am J Ind Med. 2006;49(7):535-46.

35. Fu H, Demers PA, Costantini AS, Winter P, Colin D, Kogevinas M, Boffetta P. Cancer mortality among shoe manufacturing workers: an analysis of two cohorts. Occup Environ Med. 1996:53(6):394-8.

36. Zaridze D, Bulbulyan M, Changuina O, Margaryan A, Boffetta P. Cohort studies of chloroprene-exposed workers in Russia. Chem Biol Interact. 2001; 135-136:487-503.

37. Uuksulainen SO, Heikkila PR, Olkinuora PS, Kiilunen M. Self-reported occupational health hazards and measured exposures to airborne impurities and noise in shoe repair work. Int J Occup Environ Health. 2002;8(4):320-7.

38. Walker JT, Bloom TF, Stern FB, Okun AH, Fingerhut MA, Halperin WE. Mortality of workers employed in shoe manufacturing. Scand J Work Environ Health. 1993:19(2):89-95.

39. Dosemeci M, Wacholder S, Lubin JH. Does nondifferential misclassification of exposure always bias a true effect toward the null value? Am J Epidemiol. 1990;132(4):746-8. 